\title{
Therapeutic Plasma Exchange Combined with Total Thyroidectomy to Rescue a Case of Thyroid Storm Intolerant to Antithyroid Drugs
}

\author{
Xiaoxia $\mathrm{Hu}^{1}$, Haidong Wang ${ }^{2}$, Jie $\mathrm{Li}^{1}$, Hong Shi ${ }^{1}, \mathrm{Xia} \mathrm{Liu}^{1}$ and Jirui He${ }^{1}$ \\ ${ }^{1}$ Department of Endocrinology, Second Hospital of Lanzhou University, China \\ ${ }^{2}$ Department of Anesthesiology, Gansu Cancer Hospital, China
}

\begin{abstract}
Thyroid storm is a syndrome related to acute exacerbation of thyrotoxicosis for which timely diagnosis and treatment are crucial. Importance of antithyroid drug therapy in thyroid storm patients has been emphasised in clinical treatments for a long time. These patients should receive definitive therapy for their underlying hyperthyroidism to avoid recurrence after controlling thyroid storm. However, the curative effect of antithyroid medication is sometimes limited because of rare or serious side effects or failure to control disease progression, resulting in few treatment alternatives. We present a case of an old woman with thyroid storm and antithyroid drug intolerance, which was successfully managed using a combination of plasma exchange and thyroidectomy. It confirms the significant benefits of therapeutic plasma exchange (TPE) when clinical conditions do not allow routine treatment of thyroid storm. This procedure is safe and effective when performed preoperatively as a rescue measure for thyroid storm patients.
\end{abstract}

Key Words: Thyroid storm, Drug intolerance, Plasma exchange, Total Thyroidectomy.

How to cite this article: Hu X, Wang H, Li J, Shi H, Liu X, He J. Therapeutic Plasma Exchange Combined with Total Thyroidectomy to Rescue a Case of Thyroid Storm Intolerant to Antithyroid Drugs. J Coll Physicians Surg Pak 2020; 30(05):532-534. DOI: https://doi.org/10.29271/jcpsp.2020.05.532.

\section{INTRODUCTION}

Hyperthyroidism, thyrotoxicosis and thyroid storm are a continuum of disease. ${ }^{1,2}$ Thyroid storm, as an endocrine critical illness, is a therapeutic diagnostic emergency. Timely diagnosis and treatment are the keys for successful management of the condition. ${ }^{3}$ Without treatment, mortality reaches $100 \%$ and it is $10-50 \%$ with treatment. ${ }^{4}$ There are very few options available in patients with thyroid storm, who have contraindications to anti-thyroid drugs, radioactive iodine, and thyroidectomy.

We, herein present a case of a 72-year women, who was intolerant to anti-thyroid drugs, and was treated successfully with therapeutic plasma exchange (TPE) and thyroidectomy.

\section{CASE REPORT}

A 72-year woman presented with complaints of palpitation, nausea and fatigue for three months in addition to aggravated fever and cough and orthopnea for 3 days. She was diagnosed as hyperthyroidism, hyperthyroid heart disease, arrhythmia, with cardiac function class of III. Anti-thyroid and anti-arrhythmia drugsas well as symptomatic treatment were given. However, the patient's symptoms were not relieved. Three days before admission to the hospital, the patient had fever $\left(39.5^{\circ} \mathrm{C}\right)$, chills, cough, lack of sputum, increased cough in the supine position, orthopnoea at night, and oedema of both lower extremities.

Correspondence to: Jirui He, Department of Endocrinology,

Second Hospital of Lanzhou University, China

E-mail: hjrlzys63@163.com

Received: March 26, 2019; Revised: August 20, 2019;

Accepted: August 26, 2019

DOI: https://doi.org/10.29271/jcpsp.2020.05.532
Routine blood analysis showel white blood cell (WBC) count of $2 \times 10^{9} / \mathrm{L}$. The patient was hospitalised for further treatment. Physical examinations showed temperature $38.5^{\circ} \mathrm{C}$; heart rate (HR) : 91 beats/min; breaths (R): 20 times/min and blood pressure (BP) : $90 / 60 \mathrm{mmHg}$. The patient did not have any eye symptoms and had normal tonsils; however, she showed signs of pharyngeal congestion and slight yellowing of the skin and mucosa throughout the body. The thyroid was not palpable. Her HR (91 beats/min) was irregular with audible and premature beats at 3 beats/min. Lung and abdominal examinations revealed no obvious anomalies. There was oedema of both lower limbs. Laboratory tests revealed: $\mathrm{Na}+$ : $133.8 \mathrm{mmol} / \mathrm{L}$ (normal range: 135-145mmol/l); K+ : 2.97 $\mathrm{mmol} / \mathrm{L}$ (normal range: 3.5-5.5mmol/l); Total bilirubin (TBIL) : $36.1 \mathrm{mmol} / \mathrm{L}$ (normal range: $3.0-25.8 \mathrm{mmol} / \mathrm{l}$ ), Direct bilirubin (DBIL) : $24.7 \mathrm{mmol} / \mathrm{L}$ (normal range:0-6.8mmol/l); Alanine aminotransferase (ALT): $409 \mathrm{U} / \mathrm{L}$ (normal range: <50 U/L); Aspartate aminotransferase (AST): $227 \mathrm{U} / \mathrm{L}$ (normal range: $<50 \mathrm{U} / \mathrm{L}$ ); and Glutamyl transferase (GGT) : $284 \mathrm{U} / \mathrm{L}$ (normal range: <120 U/L). Routine blood analysis revealed: WBC: $1.35 \times 10^{9} / \mathrm{L}$ and Neutrophilic granulocytes of (NE): $0.79 \times 10^{9} / \mathrm{L}$. Random urine analysis revealed: Urobilinogen (URO): $33 \mu \mathrm{mol} / \mathrm{L}$ (normal range: 3.2-16umol/l). Electrocardiography (ECG) revealed sinus arrhythmia, premature ventricular contractions, and ST-T changes. Thyroid static imaging findings were consistent with hyperthyroidism. The thyroid function tests are shown in Table I. The patient was diagnosed with hyperthyroidism, thyroid crisis, hyperthyroid heart disease, arrhythmis, grade III cardiac function, neutropenia, liver damage, and electrolyte inbalance. WBCs and liver function became normal after treatment was given to protect the liver, which raised leukocytes. The general condition of the patient improved after anti-arrhythmis and improved cardiac function treatment. 


\begin{tabular}{|c|c|c|c|c|c|c|c|c|}
\hline & $\begin{array}{c}\text { TSH } \\
\mathrm{ulU} / \mathrm{ml}\end{array}$ & $\begin{array}{c}\mathrm{TT3} \\
\mathrm{nmol} / \mathrm{L}\end{array}$ & $\begin{array}{c}\mathrm{TT4} \\
\mathrm{nmol} / \mathrm{L}\end{array}$ & $\begin{array}{c}\text { FT3 } \\
\text { pmol/L }\end{array}$ & $\begin{array}{c}\text { FT4 } \\
\mathrm{pmol} / \mathrm{L}\end{array}$ & $\begin{array}{c}\text { TG } \\
\mathrm{ng} / \mathrm{ml}\end{array}$ & $\begin{array}{c}\text { ATG-Ab } \\
\text { U/ml }\end{array}$ & $\begin{array}{l}\text { TPO-Ab } \\
\text { U/ml }\end{array}$ \\
\hline Before plasma exchange & 0.002 & 6.17 & 231.1 & 22.3 & 54.59 & 137 & $<15$ & 28 \\
\hline $6 \mathrm{~h}$ after the first plasma exchange & 0.004 & 3.32 & 169.3 & 13.46 & 40.95 & 44.8 & 16 & 58 \\
\hline $12 \mathrm{~h}$ after the first plasma exchange & 0.008 & 4.13 & 161.1 & 18.08 & 38.94 & 43.5 & $<15$ & 53.5 \\
\hline $36 \mathrm{~h}$ after the first plasma exchange & 0.003 & 3.05 & 167.8 & 14.22 & 37.11 & 51.9 & $<15$ & 29 \\
\hline $\begin{array}{l}\text { Before the second plasma } \\
\text { exchange }\end{array}$ & 0.002 & 4.93 & 176.3 & 17.68 & 39.14 & 67.1 & $<15$ & 31 \\
\hline $\begin{array}{l}\text { 6h after the second plasma } \\
\text { exchange }\end{array}$ & 0.005 & 3.12 & 182.2 & 15.49 & 39.43 & 30.8 & $<15$ & $<28$ \\
\hline $\begin{array}{l}12 \mathrm{~h} \text { after the second plasma } \\
\text { exchange }\end{array}$ & 0.009 & 4.1 & 182.8 & 18.26 & 44.14 & 31 & $<15$ & $<28$ \\
\hline Before the third plasma exchange & 0.006 & 2.39 & 153.1 & 10.98 & 35.45 & 22.4 & $<15$ & $<28$ \\
\hline $\begin{array}{l}24 \mathrm{~h} \text { after the third plasma } \\
\text { exchange }\end{array}$ & 0.005 & 1.5 & 146.5 & 5.51 & 42,88 & 21.3 & $<15$ & $<28$ \\
\hline $24 \mathrm{~h}$ after surgery & 0.003 & 1.16 & 114 & 4.51 & 23.43 & 18.7 & $<15$ & $<28$ \\
\hline Normal range & $0.55-4.78$ & $0.59-2.79$ & $58.10-140.6$ & $3.5-6.5$ & $11.5-22.7$ & $0.83-68$ & $0-60$ & $0-60$ \\
\hline
\end{tabular}

$\Pi T 3=$ Triiodothyronine; $T T 4=$ Total thyroxine; $F T 3=$ Free triiodothyronine; $F T 4=$ Free thyroxine; $T S H=$ Thyriod stimulating hormone; $T P O=$ Thyroid peroxidase antibody; $T$ G = Thyroglobulin; $A T G=$ Thyrog .

After treatment with anti-thyroid drugs again, the patient experienced intolerable nausea, vomiting, joint pain, neutropenia, and abnormal liver functions, leading to the diagnosis of thyroid storm with anti-thyroid drug intolerance.

After three plasma exchanges, thyroid hormone levels became normal. Total thyroidectomy was performed, and the patient's condition was stable during and after surgery. After reviewing the patient's thyroid hormone function, thyroid hormone replacement therapy was started, after which the patient was discharged.

\section{DISCUSSION}

TPE is used to treat many diseases with the aim to quickly and effectively reduce hormone levels, antibodies and other harmful substances in the blood. During the course of plasma exchange, the patient's plasma is replaced with a colloidal replacement solution (in this case, albumin). Thyroxine-binding globulin (TBG), with bound thyroid hormones, is removed with the plasma. The affinity of albumin for thyroid hormones is far less than that of TBG, thereby providing a much larger capacity for low-affinity binding that may help lower free thyroid hormone levels. TPE should be performed either every day or every 2-3 days until clinical improvement, as defined by the American Society for Apheresis (ASFA), ${ }^{5}$ because it is a reasonably safe procedure. This study showed that thyroid hormone levels significantly decreased at $36 \mathrm{~h}$ after plasma exchange, with subsequent slight increase at 48 hours. However, this effect did not last long. TPE is considered only an effective adjunctive treatment to provide clinical stabilisation until drug efficacy can be achieved or before definitive management with thyroidectomy. ${ }^{6}$ TPE has shown a significant benefit in hyperthyroid crisis, induced by Graves' disease. ${ }^{7}$

Graves' disease patients, who present a hyperthyroid crisis and have failed on medical treatment or are unable to tolerate conventional medical treatments, surgeries or radioiodine therapy, may respond well to plasma exchange, which results in clinical and biochemical stabilisation of the disease process. After completing three plasmapheresis treatments, the patient exhibited a remarkable decline in free T4, free T3, and total T3 levels. In particular, free T3 and total T3 levels returned to the normal reference range (Table I).

TPE should be considered as a stabilising measure for those patients where treatment has failed or for those who cannot tolerate routine treatments. Plasma exchange results in improvement of symptoms as well as decrease in thyroid hormone levels, providing a window for the effective treatment of a hyperthyroid crisis. Current case reports and randomised 
studies of plasma exchange in thyroid storm patients lack clear regulations for relevant indications. The optimal start time and duration of treatment for TPE remain undetermined. Further research is warranted to determine the optimal time interval and greatest possible benefit for each patient.

\section{PATIENT'S CONSENT:}

Informed consent was taken from the patient for publication of this case.

\section{CONFLICT OF INTEREST:}

Authors declared no conflict of interest.

\section{REFERENCES}

1. Maguy Chiha. Thyroid storm: An updated review. J Intensive Care Med 2015; 30(3):131-40.

2. Idrose A. Acute and emergency care for thyrotoxicosis and thyroid storm. Acute Med Surg 2015; 2(3):147-57.

3. Nayak B, Burman K. Thyrotoxicosis and thyroid storm. Endocrin Metab Clin North Am 2006; 35(4):663-86.

4. Taylor GM. Pop AMC. Mcdowell EL. High-output congestive heart failure: A potentially deadly complication of thyroid storm. Oxf Med Case Reports 2019; 2019(6):252-55.

5. Schwartz J, Winters JL, Padmanabhan A. Guidelines on the use of therapeutic apheresis in clinical practice: Evidence-based approach from the writing committee of the American Society for Apheresis: The sixth special issue. J Clin Apher 2013; 28(3):145-284.

6. Muller C, Perrin P, Faller B, Richter S, Chantrel F. Role of plasma exchange in the thyroid storm. Ther Apher Dial 2011; 15(6):522-31.

7. Szczepiorkowski ZM, Bandarenko N, Kim HC. Guidelines on the use of therapeutic apheresis in clinical practice: Evidencebased approach from the apheresis applications committee of the American Society for Apheresis. J Clin Apher 2007; 22: 106-75. 